\title{
Anti-diarrheal Activity of Caffeine: A Modulatory Effect with Loperamide and through 6FH5 (PIK3CG) Protein Interaction Pathway
}

\author{
Farhana Faria', Shardar Mohammad Hafiz Hassan', Rajib Hossain', Mahmuda Akter Mukta', Md. \\ Ashiqur Rahman Chowdhury ${ }^{2}$, Muhammad Torequl Islam ${ }^{1, *}$
}

1Department of Pharmacy, Life Science Faculty, Bangabandhu Sheikh Mujibur Rahman Science and Technology University, Gopalganj, Dhaka, BANGLADESH.

${ }^{2}$ Department of Chemistry, University of Chittagong, Chittagonj, BANGLADESH.

\begin{abstract}
Background: Caffeine (CAF) is known for its central nervous system stimulatory effect. Although, CAF use in diarrhea, especially in Runner's diarrhea is still controversial, but it has been reported that dark tea containing CAF has anti-diarrheal effect on Sennaemediated diarrhea in mice. Aim: To evaluate the anti-diarrheal effect of CAF and its modulatory effects on the standard anti-diarrheal drug loperamide (LOP), an opioid receptor agonist. Materials and Methods: CAF (15 mg/kg, i.p.) with or without LOP (3 $\mathrm{mg} / \mathrm{kg}$, p.o.) was administered to the Swiss mice (Mus musculus) previously treated with castor oil. Additionally, an in silico study was also performed to see the possible anti-diarrheal mechanism of CAF and LOP. Results: CAF increased the latent period, while decreasing the diarrheal defecation during the observation period ( $4 \mathrm{hr}$ ) in the test animals. Interestingly, CAF co-treated with the LOP exhibited a prominent anti-diarrheal effect in comparison to the negative control, CAF and LOP groups. Further, in silico study suggests that CAF have the most binding affinity with the 6FH5 (PIK3CG) protein $(-8.22$ $\mathrm{KJ} / \mathrm{mol}$ ) of adenosine receptor, while LOP with the $\mu$-opioid receptor. Conclusion: CAF showed significant anti-diarrheal effect as well as strengthen the anti-diarrheal effect of LOP in castor oil-induced diarrheal mice. Protein 6FH5 might be the best conformor for the CAF in the treatment of diarrhea.
\end{abstract}

Key words: Mus musculus, Caffeine, Castor oil, Diarrhea, Adenosine receptor.

\section{INTRODUCTION}

Diarrhea results three to more unformed stools in a day along with other stomachic symptoms. ${ }^{1}$ Most often diarrhea lasts for a few days and results in dehydration. The process of dehydration causes loss of essential fluid and electrolytes from our body. Therefore, diarrhea is one of the lifethreatening diseases in the world. Diarrhea occurs mostly in the developing countries and causes an economic burden on the poor patients. ${ }^{2}$ Diarrhea is also evident to cause nausea, vomiting and abdominal cramps, thereby, forces the patients into bed rest. ${ }^{3}$

Generally, diarrhea is caused by an infection in the intestines by one or more pathogen (e.g., virus, bacterium, or parasite) or to gastroenteritis. These infectious agents are mostly acquired from the contaminated foods or water. Diarrhea alters the transportation process of water and essential electrolytes in our body, results hyper-secretory responses and giant contraction in the intestine. An ideal anti-diarrheal agent can correct the altered situations in our intestine. ${ }^{4}$ Commonly used anti-diarrheal agents (e.g., loperamide, nifedipine, prazosin, propranolol) can cause a number of mild to severe side effects, such as nausea, vomiting, dizziness, drowsiness, tiredness, abdominal pain, constipation, abnormalities in heartbeat and so on.
Submission Date: 21-12-2019; Revision Date: 13-05-2020; Accepted Date: 02-10-2020

DOI: 10.5530/ijper.54.3s.160 Correspondence:

Dr. Muhammad Torequl Islam

Department of Pharmacy, Life Science Faculty, Bangabandhu Sheikh Mujibur Rahman Science and Technology University, Gopalganj, Dhaka-8100, BANGLADESH.

Phone: +880-1793-726407

E-mail: dmt.islam@bsmrstu. edu.bd

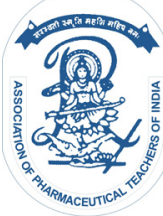

www.ijper.org 
Caffeine $\quad\left(\mathrm{C}_{8} \mathrm{H}_{10} \mathrm{~N}_{4} \mathrm{O}_{2}:\right.$ 1,3,7-trimethylxanthine or 3,7-dihydro-1,3,7-trimethyl-1H-purine-2,6-dione), an adenosine receptor antagonist that acts centrally as a stimulant in our body. ${ }^{5}$ Caffeine (CAF) has many important biological effects, including long-term memory enhancing, ${ }^{6}$ health protecting effects, ${ }^{7}$ and so on. It has been demonstrated that CAF intake may associate with some reversible and short-term physiological effects in our body. However, a moderate CAF intake is assumed to be safe in some diseases, including cardiovascular disease. ${ }^{8}$

One study reports that abuse of CAF may cause diarrhea in human. ${ }^{9}$ However, there is a lack of scientific evidence behind this fact. On the other hand, to avoid CAF during Runner's diarrhea (acute exercise-induced diarrhea) is still controversial. ${ }^{10}$ In contrary, in a recent study, the effect of dark tea in Folium Sennae mediated diarrhea in mice was investigated, suggesting the tea extract significantly progressed the diarrheic phenomena (e.g., loose stools, diarrheal index, intestine peristalsis) in moderate to high- dose groups. It may be due to the high amount of CAF and gallocatechin present in it. ${ }^{11}$ Upon understanding the needs, this study aims to evaluate anti-diarrheal effect of CAF in mice pre-treated with castor oil. The interaction capacity of CAF with the commonly used anti-diarrheal drug loperamide has been also investigated. Additionally, in silico study has been also performed to see the possible anti-diarrheal mechanism of CAF.

\section{MATERIALS AND METHODS}

\section{Reagents and chemicals}

Castor oil was purchased from a local market of Bangladesh. Loperamide (LOP, IMOTIL ${ }^{\circledR} 2 \mathrm{mg}$ Cap.) was purchased from the Square Pharmaceuticals Ltd., while CAF was collected from the ACME Laboratories Ltd., Bangladesh.

\section{Experimental animals}

Adult male albino mice (18-24g), purchased from the Jahangir Nagar University (JU), Dhaka, were used in this study. The animals were kept in room having temperature: $25 \pm 2{ }^{\circ} \mathrm{C}$, humidity: $50 \pm 5 \%$ and $12 \mathrm{hr}$ dark/light cycle. Standard diet and water were provided to the animals. They were subjected to this study after seven days (acclimatization period). The animals were randomly grouped into the test and control groups and the food was withdrawn $12 \mathrm{hr}$ before the experimental hours.

\section{Groups and treatments (castor oil-induced diarrhea in mice)}

This study was done according to the method established by Awouters et al. ${ }^{12}$ with slight modifications. Briefly, each animal was treated with $0.5 \mathrm{~mL}$ castor oil $30 \mathrm{~min}$ after the sample (Gr-II) and controls (Gr-I and Gr-III) treatment. Similarly, CAF (Gr-II) was co-treated (before 15 min) with Gr-III (Table 1$)$. The animals $(n=5)$ were then observed for latency and total defecation up to 4 hr.

\section{Computational study}

In this case the binding mechanism of the CAF and LOP was determined against the therapeutic target receptors adenosine receptor (AR) and $\mu$-opioid receptor ( $\mu$-OR), respectively.

\section{Source of ligand and macromolecule}

Ligand, CAF, was selected from the PubChem online database and crystallographic structure were downloaded in 'sdf' format. The protein, targeted receptor, were retrieved from the protein data bank, online database (www.rcsb.com). The target of the drug was retrieved drug bank in which specific receptor is selected. Crystallographic structure was collected in 'pdb' format.

\section{Software and materials}

Schordinger Suite version, Maestro 10.1, was subjected to perform ligand and protein preparation, grid generation and molecular docking study. ${ }^{13}$ Drug discovery studio (version discovery studio 4.5), primary tools in drug discovery, has been utilized in various ligand- and structure-based methods for ameliorating pharmacophore modeling, virtual screening and nonbonding interaction. ${ }^{14}$

\section{Ligand preparation}

We targeted to select an adenosine receptor antagonist. $\mathrm{CAF}$ is considered as an adenosine receptor antagonist. ${ }^{15}$ CAF (Pubchem CID: 2519), was incorporated in

Table 1: Animals fasting overnight are treated with the following substances at $10 \mathrm{~mL} / \mathrm{kg}$.

\begin{tabular}{|c|c|}
\hline Treatment groups & Dose \\
\hline Gr-I: VEH (i.p.) & $10 \mathrm{~mL} / \mathrm{kg}$ \\
\hline Gr-II: CAF (i.p.) & $15 \mathrm{mg} / \mathrm{kg}$ \\
\hline Gr-III: LOP (p.o.) & $3 \mathrm{mg} / \mathrm{kg}$ \\
\hline Gr-IV: CAF (i.p.) + LOP (p.o.) & $15 \mathrm{mg} / \mathrm{kg}+3 \mathrm{mg} / \mathrm{kg}$ \\
\hline
\end{tabular}

VEH: $0.05 \%$ Tween 80 in $0.9 \% \mathrm{NaCl}$ solution; CAF: Caffeine; LOP: Loperamide; i.p.: Intra-peritoneal; p.o.: Per oral 
the Schordinger software for the preparation of ligand. Compounds' three dimensional structures were developed by using Ligprep 2.5 in Maestro v10.1 with force field OPLS_2005. Human $\mu$-opioid receptor ( $\mu$-OR) was obtained via structure-preparation module implemented in $\mathrm{MOE}^{16}$ followed by the protonation, minimization and Amber 99 partial charge application.

\section{Protein preparation}

Three dimensional crystal structure of macromolecule 1TB5 (PDE4B) Homo sapiens, 2YDO(ADORA2A) Homo sapiens, 3JWQ(PDE5A) Homo sapiens, 3PWH(ADORA2A) Homo sapiens, 3UZC(ADORA2A) Homo sapiens, 4DDF(pduT) Salmonella typhimurium, 4DKL(Oprm1) Mus musculus, Enterobacteria phage T4, 4DO9(POLB) Homo sapiens, 4UKK(RPS0A) Homo sapiens, 4UUU(CBS) Homo sapiens, 4UVC(KDM1A ) Homo sapiens, 5HES(MAP3K20) Homo sapiens, 5UKL(GRK2) Homo sapiens, 6DDE(GNAI1) Homo sapiens, 2WEY(PDE1B) Homo sapiens, 2JBZ(acpS) Streptomyces coelicolor, 3K4S(PDE4D) Homo sapiens, 3REY(ADORA2A) Homo sapiens, 4NPV(PDE1B) Homo sapiens, 5C1M(Oprm1) Mus musculus, 5G55(Oprm1) Mus musculus, 5UPO(PDE1B) Homo sapiens, 6FH5(PIK3CG) Homo sapiens, 3UZA(ADORA2A) Homo sapiens, 3RFM(ADORA2A) Homo sapiens were selected from the protein data bank and converted into 'pdb' format. Then the 'pdb' file of protein is applied in Maestro version 10.1 for the preparation of each protein. ${ }^{17}$ Bond orders and charges were accredited and hydrogen atoms were combined to the heavier atoms. The minimization was done by using the force field OPLS_2005 through setting most heavy atom RMSD (root-mean-squaredeviation) to $0.30 \AA$.

\section{Validating of active side and grid generation}

Active side was validated properly due to having a great importance in moleculer docking study. Several binding sites were available in protein and then we selected one of the binding sites for the grid generation. The grids were developed by maintaining the default parameters of van der Waals scaling factor 1.00 and charge cutoff 0.25 subjected to OPLS 2005 force field. A threedimensional bounding box $(15 \AA \times 15 \AA \times 15 \AA)$ was generated for the receptor.

\section{Glide docking}

Glide Standard Precision (SP) ligand docking was performed in Schrödinger-Maestro v10.1 to claim the binding affinity and bind energy. The higher the negative value of the glide score the more the binding affinity of the drug with the selected protein.

\section{Frequency and optimization of ligand}

The frequency and optimization of CAF have been carried out with GAUSSIAN 09 software. ${ }^{18}$ B3LYP method with 6-31G $(\mathrm{d}, \mathrm{p})$ basis set was chosen to predict optimized structure, vibrational frequency analysis, HOMO-LUMO gap, chemical potentials. ${ }^{19,20}$ The vibrational bands are calculated by applying Guess view molecular visualization program. ${ }^{21}$

\section{IR frequency}

The infra-red frequencies of CAF were calculated without scaling factor by using the density functional theory method (Figure 1).

The energies of HOMO, LUMO (Structure: Figure $2)$, hardness, softness and chemical potential ${ }^{22-24}$ were calculated by using B3LYP/6-31G (d,p) (Table 2).

\section{Statistical analysis}

For the in vivo study, we performed one-way analysis of variance (ANOVA) and the results are expressed as mean \pm standard deviation (SD). Newman-Keuls post hoc test was performed by using the software GraphPadPrism ${ }^{\circledR}$ - GraphPad Software, Inc. (Version: 6.0), considering $p<0.05$ at $95 \%$ confidence intervals.

\section{RESULTS \\ Castor oil-induced diarrhea}

CAF and the standard drug LOP significantly $(p<0.05)$ increased latent periods in diarrheal mice as compared to the VEH group. CAF at $15 \mathrm{mg} / \mathrm{kg}$ (i.p.) showed latent period $33.62 \pm 4.43 \mathrm{~min}$, which was $24.93 \%$ more than the LOP group. CAF when co-treated with the LOP $3 \mathrm{mg} / \mathrm{kg}$ (p.o.) increased latency periods 35.75 and $51.77 \%$ more than the CAF and LOP groups, respectively (Table 3).

Table 4 indicates that CAF at $15 \mathrm{mg} / \mathrm{kg}$ significantly $(p<0.05)$ reduces diarrheal secretions in comparison to the VEH group. The highest reduction of diarrheal secretions by CAF was observed on the $4^{\text {th }} \mathrm{hr}$ (4.48 \pm 1.08 ). More reduction of diarrheal secretions was observed in LOP group. The results also revealed that CAF co-treated with the standard drug LOP effectively reduced diarrheal secretions in comparison to the CAF and LOP groups in all respective observation hours. CAF + LOP was seen to stop diarrheal secretion at the $4^{\text {th }} \mathrm{hr}$ in test animals.

\section{In silico study}

In the IR spectrum CAF showed the highest frequency at $1750 \mathrm{~cm}^{-1}$ which is comparable to a result obtained from a Fourier transform infra-red spectroscopy (FTIR) 
analysis, where the absorbance band was found at 1655 $\mathrm{cm}^{-1}$ at 5 ppm sensitivity technique. The thermodynamic properties of CAF were calculated: Free energy: -680.240968 Hartree, Enthalpy: -680.188514 Hartree and Dipole moment: 3.5390 Debye. CAF has also a low HOMO-LUMO gap (0.19). In molecular docking study, for the visualization of the ligand and protein, Discovery studio software (e.g., Discovery studio visualizer v16.1.0.15350 data) plays a significant role. The molecular docking is done by the schordinger v 10.1 and glide score are shown in the Table 5. Our findings suggest that $\mathrm{CAF}$ has highest binding affinity with 6FH5 (PIK3CG) receptor (binding affinity: -8.22 $\mathrm{kj} / \mathrm{mol}$ ). CAF has reasonable binding energy with this receptor which accounts for -32.839 . The docking scores of 3PWH, 2JBZ and 5G55 receptors with CAF were $-8.088,8.15$ and $7.88 \mathrm{kj} / \mathrm{mol}$, respectively.

In biological science, hydrogen bond plays a crucial role in DNA structure. Our study suggests that the CAF6FH5 (PIK3CG) complex have well organized hydrogen bond. The strong hydrogen bond was recognized in the
VAL882 (1.92514), ILE881 (2.80903) and GLU880 (2.44) amino acid residues. Several hydrophobic bonds were also present in MET953 (3.59417), TYR867 (5.34636), ILE963 (5.44852) amino acid residues. Binding affinities and non-bonding interactions are shown in Table 5 and 6 and Figure 3.

From our study, it is clear that, CAF has the most binding affinity with the 6FH5 (PIK3CG) protein. This CAF6FH5 complex have a significant amount of hydrogen bond, expressing the strong binding interaction between the CAF and receptor. The receptor $\mu$-OR represents an important opioid target for the occurrence of pain, diarrhea, chronic pulmonary edema, cough and shivering. Shown in Figure 4 are molecular docking results of $\mu$-OR with LOP. For LOP, docking results show multiple hydrophobic interactions with the $\mu$-OR. In addition, the methyl group of VAL236, ILE296, VAL300 and ILE322 display hydrophobic interactions with the aromatic rings of LOP while TRP293 and TYR326 show $\pi-\pi$ stacking.

\begin{tabular}{|c|c|c|c|c|c|c|}
\hline $\begin{array}{l}\text { Compound } \\
\text { Name }\end{array}$ & номо & LUMO & GAP & Hardness $(\eta)$ & $\begin{array}{l}\text { Softness } \\
\text { (S) }\end{array}$ & $\begin{array}{l}\text { Chemical } \\
\text { Potential }(\mu)\end{array}$ \\
\hline Caffeine & -0.22 & -0.03 & 0.19 & 0.08 & 12.78 & -0.24 \\
\hline
\end{tabular}

\begin{tabular}{|c|c|}
\hline Treatment groups & Latency (min) \\
\hline VEH & $10.22 \pm 2.78$ \\
\hline CAF & $33.62 \pm 4.43^{\mathrm{ac}}$ \\
\hline LOP & $25.24 \pm 1.58^{a}$ \\
\hline $\mathrm{CAF}+\mathrm{LOP}$ & $52.33 \pm 3.23^{\mathrm{abc}}$ \\
\hline
\end{tabular}

Values are mean $\pm \mathrm{SD}(n=5)$; one way ANOVA followed by Newman-Keuls post hoc test; $p<0.05$ when compared to the ${ }^{\mathrm{a}} \mathrm{Gr}-\mathrm{I}$, ${ }^{\mathrm{G}} \mathrm{Gr}-\mathrm{II},{ }^{\mathrm{c}} \mathrm{Gr}-\mathrm{III}$; VEH: $0.05 \%$ tween-80 in $0.9 \% \mathrm{NaCl}$ solution; CAF: Caffeine; LOP: Loperamide

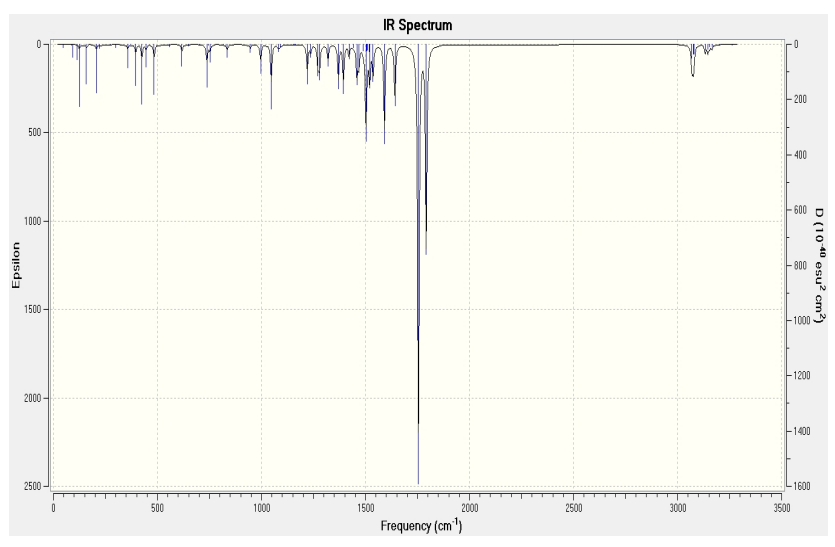

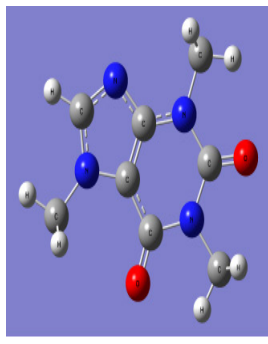

Optimized

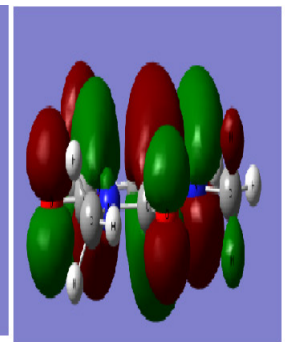

HOMO

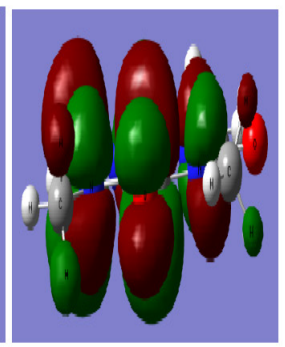

LUMO

Figure 2: Optimized, HOMO and LUMO structures of CAF.

Figure 1: Infra-red frequency of caffeine. 


\section{DISCUSSION}

The castor oil test has been used for years for the screening and evaluation of anti-diarrheal drugs. Castor oil increases the overall secretion of water and essential electrolytes along with the stimulation of peristalsis and hastening the intestinal transit. ${ }^{25}$ The pancreatic lipase hydrolyzed castor oil glycerol and ricinoleic acid after ingestion. Ricinoleic acid is responsible for the diarrheal effect in animals. ${ }^{26} \mathrm{It}$ is due to it can release prostaglandins and platelet-activating factor, ${ }^{25}$ thereby, causes smooth muscle contractionin the small intestine. ${ }^{27}$ It also promotes the release of nitric oxide (NO) and activation

\begin{tabular}{|c|c|c|c|c|}
\hline $\begin{array}{l}\text { Treatment } \\
\text { groups }\end{array}$ & $1^{\text {st }} h$ & $2^{\text {nd }} h$ & $3^{\text {rd } h}$ & $4^{\text {th }} h$ \\
\hline VEH & $16.23 \pm 2.44$ & $12.38 \pm 2.68$ & $10.78 \pm 1.57$ & $8.48 \pm 2.74$ \\
\hline CAF & $6.78 \pm 1.59^{a}$ & $6.23 \pm 1.08^{a}$ & $5.62 \pm 1.08^{a}$ & $4.48 \pm 1.08^{a}$ \\
\hline LOP & $4.19 \pm 2.38^{\mathrm{ab}}$ & $3.78 \pm 2.68^{\mathrm{ab}}$ & $1.84 \pm 1.36^{\mathrm{ab}}$ & $1.44 \pm 1.78^{\mathrm{ab}}$ \\
\hline CAF+LOP & $1.23 \pm 0.19 \mathrm{abc}$ & $1.21 \pm 0.18^{a b c}$ & $0.20 \pm 0.22^{\mathrm{abc}}$ & $0.00 \pm 0.00^{\mathrm{abc}}$ \\
\hline
\end{tabular}

Values are mean $\pm \operatorname{SEM}(n=5)$; one way ANOVA followed by Newman-Keuls post hoc test; $p<0.05$ when compared to the ${ }^{a} \mathrm{Gr}-\mathrm{I},{ }^{\mathrm{b}} \mathrm{Gr}-\mathrm{II},{ }^{\mathrm{c}} \mathrm{Gr}-\mathrm{III}$ in respective hour; VEH: $0.05 \%$ tween-80 in $0.9 \% \mathrm{NaCl}$ solution; CAF: Caffeine; LOP: Loperamide

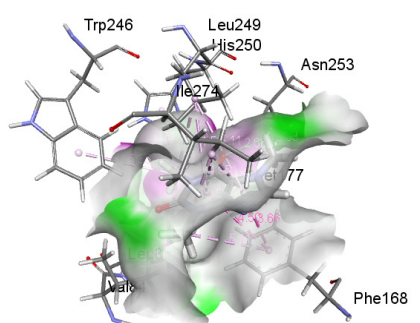

CAF-3PWH

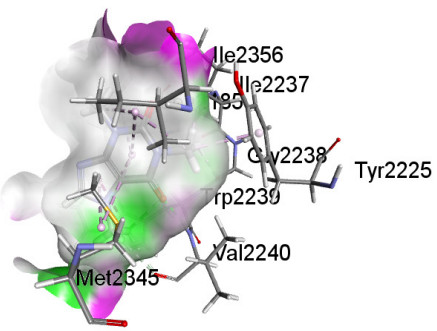

CAF-2JBZ

Figure 3: Non-bonding interactions of caffeine (CAF) with 3PWH, 6FH9, 5G55 and 2JBZ proteins (discovery studio visualizer v16.1.0.15350).

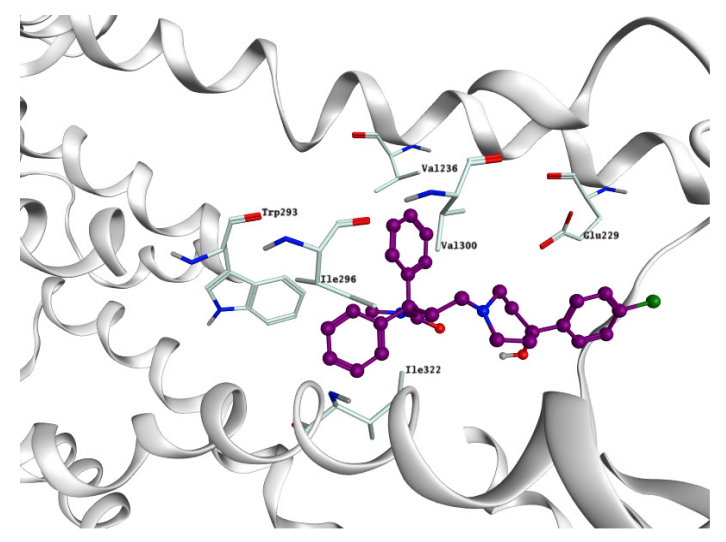

Figure 4: Molecular docking interaction of the $\mu$-opioid receptor with loperamide.

\begin{tabular}{|c|c|c|}
\hline Proteins & $\begin{array}{l}\text { Binding } \\
\text { energy }\end{array}$ & $\begin{array}{l}\text { Docking } \\
\text { score }\end{array}$ \\
\hline 1TB5 (PDE4B) Homo sapiens & -31.382 & -4.886 \\
\hline 3JWQ(PDE5A) Homo sapiens & -33.818 & -5.421 \\
\hline 3PWH(ADORA2A) Homo sapiens & -30.086 & -8.088 \\
\hline 3UZC(ADORA2A) Homo sapiens & -28.26 & -7.599 \\
\hline $\begin{array}{c}\text { 4DDF(pduT) Salmonella } \\
\text { typhimurium }\end{array}$ & -25.383 & -6.13 \\
\hline $\begin{array}{c}\text { 4DKL(Oprm1) Mus musculus, } \\
\text { Enterobacteria phage T4 }\end{array}$ & -22.698 & -5.752 \\
\hline 4DO9(POLB) Homo sapiens & -32.33 & -5.915 \\
\hline 4UKK(RPSOA) Homo sapiens & -28.271 & -6.664 \\
\hline 4UUU(CBS) Homo sapiens & -28.808 & -6.313 \\
\hline 4UVC(KDM1A) Homo sapiens & -32.14 & -6.445 \\
\hline 5HES(MAP3K20) Homo sapiens & -29.781 & -6.395 \\
\hline 5UKL(GRK2) Homo sapiens & -32.618 & -6.587 \\
\hline 6DDE(GNAl1) Homo sapiens & -25.879 & -6.163 \\
\hline 2WEY(PDE1B) Homo sapiens & -35.858 & -5.805 \\
\hline $\begin{array}{c}\text { 2JBZ(acpS) Streptomyces } \\
\text { coelicolor }\end{array}$ & -32.704 & -8.158 \\
\hline 3K4S(PDE4D) Homo sapiens & -32.328 & -5.48 \\
\hline 3REY(ADORA2A) Homo sapiens & -27.745 & -7.423 \\
\hline 4NPV(PDE1B) Homo sapiens & -29.745 & -4.694 \\
\hline 5C1M(Oprm1) Mus musculus & -24.481 & -6.051 \\
\hline 5G55(Oprm1) Mus musculus & -33.836 & -7.886 \\
\hline 5UPO(PDE1B) Homo sapiens & -35.359 & -5.477 \\
\hline 6FH5(PIK3CG) Homo sapiens & -32.839 & -8.22 \\
\hline 3UZA(ADORA2A) Homo sapiens & -29.719 & -7.375 \\
\hline 3RFM (ADORA2A) Homo sapiens & -29.054 & -7.743 \\
\hline
\end{tabular}


of adenylyl cyclase which causes an increase in cyclic adenosine monophosphate (cAMP) concentration. The increased cAMP level (a) stimulates intestinal peristaltic activity, (b) changes membrane permeability, (c) reduces $\mathrm{Na}^{+} \mathrm{K}^{+}$ATPase pump activity, leading to decrease in $\mathrm{Na}^{+}$and $\mathrm{K}^{+}$absorption. The overall factors cause an accumulation of water, $\mathrm{Na}^{+}$and $\mathrm{K}^{+}$in the lumen of the intestine. . $^{28,29}$

CAF is evident to decrease the production and release of $\mathrm{NO}$ in experimental animals. ${ }^{30}$ Moreover, CAF is also found to decrease the levels of pro-inflammatory mediators, including inducible nitric oxide synthase (iNOS), cyclooxygenase-2 (COX-2), interleukin (IL)-3, -6 and -12 and nuclear translocation of nuclear factor kappa-light-chain-enhancer of activated B cells (NF$x \mathrm{~B})$ via inhibitor of nuclear factor kappa $\mathrm{B}(\mathrm{I} \varkappa \mathrm{B} \alpha)$ phosphorylation in zebrafish. ${ }^{31} \mathrm{~A}$ short-term CAF treatment is evident to reduce adenylyl cyclase activity in mouse model. ${ }^{32}$ In a recent study, it has been seen that CAF intracts with the cAMP-induced chemotactic signal pathways in Dictyostelium, probably through multiple targets, including phosphoinositide 3-kinases (PI3K) and mammalian target of rapaycin complex 2 (mTORC2)..$^{33}$ In this study, we have seen that CAF significantly $(p<$ $0.05)$ increased the latent periods in diarrheal mice as compared to the VEH group. On the other hand, CAF when co-treated with the standards drug LOP resulted in the highest increased latency, while reducing in diarrheic secretions in castor oil induced diarrheal mice.

CAF has antioxidant $\mathrm{t}^{34}$ and anti-inflammatory $\mathrm{y}^{35}$ activities and through these effects it can protect our body from oxidative stress, pro-inflammatory and inflammatory mediators. Substances having antioxidant and antiinflammatory effects may have anti-diarrheal activities. ${ }^{36,37}$ Inflammatory bowel diseases (e.g., Crohn's disease, ulcerative colitis) also cause chronic diarrhea. CAF was found to down-regulate CHI3L1 mRNA expression, thereby, reduce in bacterial invasion in mice. ${ }^{38}$

The viral human immunodeficiency virus (HIV)-1 Trans activating factor (HIV-1 Tat) protein after activating glial cells results the release of neuroinflammatory responses, which is responsible for the diarrhea as

\begin{tabular}{|c|c|c|c|c|c|}
\hline $\begin{array}{l}\text { Ligand- } \\
\text { protein } \\
\text { complex }\end{array}$ & $\begin{array}{l}\text { Binding energy } \\
\text { (kcal/mol) }\end{array}$ & H-bond (amino acid...ligand) & $\begin{array}{c}\text { Bond } \\
\text { distance }(\AA)\end{array}$ & Hydrophobic bond & $\begin{array}{c}\text { Bond } \\
\text { distance }(\AA)\end{array}$ \\
\hline \multirow{5}{*}{ CAF-3PWH } & -8.088 & $\begin{array}{l}\text { ASN253(Conventional Hydrogen } \\
\text { Bond) }\end{array}$ & 1.78911 & $\begin{array}{l}\text { PHE168 (Pi-Pi } \\
\text { Stacked) }\end{array}$ & 4.50436 \\
\hline & & ASN253 (C-H...O) & 2.83242 & $\begin{array}{l}\text { VAL84 (Alkyl... } \\
\text { Alkyl) }\end{array}$ & 4.12047 \\
\hline & & & & $\begin{array}{l}\text { LEU85 (Alkyl... } \\
\text { Alkyl) }\end{array}$ & 5.35311 \\
\hline & & & & TRP246 (Pi-Alkyl) & 5.34899 \\
\hline & & & & HIS250(Pi-Alkyl) & 4.94156 \\
\hline \multirow{4}{*}{ CAF-6FH9 } & -8.22 & $\begin{array}{l}\text { VAL882(Conventional Hydrogen } \\
\text { Bond) }\end{array}$ & 1.92514 & MET953(Pi-Sulfur) & 3.59417 \\
\hline & & ILE881((C-H...O) & 2.80903 & $\begin{array}{l}\text { TYR867(Pi-Pi } \\
\text { T-shaped) }\end{array}$ & 5.34636 \\
\hline & & GLU880(C-H...O) & 2.44219 & $\begin{array}{l}\text { ILE881 (Alkyl... } \\
\text { Alkyl) }\end{array}$ & 4.60565 \\
\hline & & & & ILE963(Pi-Alkyl) & 5.44852 \\
\hline \multirow{3}{*}{ CAF-2JBZ } & -8.158 & $\begin{array}{l}\text { VAL2240(Conventional } \\
\text { Hydrogen Bond) }\end{array}$ & 2.00766 & $\begin{array}{l}\text { TRP2239 (Pi-Pi } \\
\text { Stacked) }\end{array}$ & 5.26535 \\
\hline & & GLY2238(C-H...O) & 2.9161 & $\begin{array}{l}\text { ILE2356 (Alkyl... } \\
\text { Alkyl) }\end{array}$ & 4.68417 \\
\hline & & & & TYR2225(Pi-Alkyl) & 5.17955 \\
\hline \multirow{3}{*}{ CAF-5G55 } & -7.88 & $\begin{array}{l}\text { VAL882 (Conventional Hydrogen } \\
\text { Bond) }\end{array}$ & 1.9619 & $\begin{array}{l}\text { TYR867 (Pi-Pi } \\
\text { T-shaped) }\end{array}$ & 5.65378 \\
\hline & & ASP964(C-H...O) & 2.28967 & $\begin{array}{l}\text { VAL882 (Alkyl... } \\
\text { Alkyl) }\end{array}$ & 5.22171 \\
\hline & & GLU880(C-H...O) & 2.686 & TYR867(Pi-Alkyl) & 3.22602 \\
\hline
\end{tabular}


well as neurotoxic effects in animals. ${ }^{39} \mathrm{CAF}$ is evident to block HIV-1 Tat protein in SH-SY5Y cells. ${ }^{40} \mathrm{CNS}$ also controls gastrointestinal motility and secretion, therefore modulates gastrointestinal functions. ${ }^{41} \mathrm{CAF}$ is widely known CNS stimulant methylxanthine alkaloid class drug, therefore, it can act through this system.

The thermodynamic properties and optimized structure of CAF suggest that it is chemically stable. ${ }^{42}$ Free energy can predict the binding properties. The more the negative values the more it is favorable to binding and interaction of the targeted protein. This study suggests CAF has higher free energy value, thus it has higher binding and interaction properties. On the other hand, if any drug has small HOMO-LUMO gap, then it will be more chemically reactive. ${ }^{43} \mathrm{CAF}$ has a small HOMO-LUMO gap, thus it will be more chemically reactive. Hydrogen bonding, a typical weak intermolecular interaction that stabilizes the energetically-favored ligands. ${ }^{44}$ The in silico study suggests that the multi-targeted small molecule CAF binds with low affinity towards the targets, especially with the 3PWH, 6FH9, 2JBZ and 5G55 proteins.

\section{CONCLUSION}

In summary, findings from this investigation suggest that $\mathrm{CAF}$ at $15 \mathrm{mg} / \mathrm{kg}$ (i.p.) displayed remarkable antidiarrheal effect in castor oil-induced diarrheal mice. It exhibited better anti-diarrheal effect when co-treated with the standard drug, LOP. We suppose, CAFmediated potentiating anti-diarrheal effects on the Swiss mice may be due to its inhibitory capacity of $\mathrm{NO}$, adenylyl cyclase and cAMP, thereby decreasing in cAMP concentration dependent stimulatory effects of intestinal peristaltic activity, alteration of the membrane permeability, thereby, reduce in $\mathrm{Na}^{+} \mathrm{K}^{+}$ATPase pump activity and an increase in water, $\mathrm{Na}^{+}$and $\mathrm{K}^{+}$levels in the lumen of the intestine in experimental animals. In silico study suggests that CAF exhibited strong binding affinity with the 6FH5 (PIK3CG) protein of the AR, while LOP with the $\mu$-OR which might be responsible for their anti-diarrheal effects in animals. We suppose, the synergistic anti-diarrheal effect of CAF and LOP may resulted through the interactive capability of CAF with AR and LOP with $\mu$-OR. More studies are highly appreciated to understand the exact molecular mechanism(s) behind the combined anti-diarrheal effect of CAF and LOP. This study accords an information regarding the safety of CAF or caffeinated products (e.g., tea, coffee etc.) during diarrhea. It also focuses on its interaction capability with the standard anti-diarrheal drug, such as LOP. Our study may provide supportive message to the future pre-clinical and clinical studies for the investigation of outcomes of CAF and CAF-related products in diarrhea.

\section{Ethical Statement}

All protocols were approved by the Ethical Committee at the Life Science Faculty, Bangabandhu Sheikh Mujibur Rahman Science and Technology University (BSMRSTU) (Approval No. 20150109015), Gopalganj, Bangladesh.

\section{ACKNOWLEDGEMENT}

We are owed to the Department of Pharmacy, Life Science Faculty, BSMRSTU, Bangladesh for providing the laboratory facilities to conduct this study.

\section{CONFLICT OF INTEREST}

The authors declare that there is no conflict of interest.

\section{ABBREVIATIONS}

$\mu$-OR: $\mu$-opioid receptor; AR: Adenosine receptor; CAF: Caffeine; cAMP: Cyclic adenosine monophosphate; COX: Cyclooxygenase; $\mathbf{I} \varkappa \mathbf{B} \alpha$ : Inhibitor of nuclear factor kappa B; IL: Interleukin; iNOS: Inducible nitric oxide synthase; LOP: Loperamide; mTORC2: Mammalian target of rapamycin complex 2; NF- $\boldsymbol{x} \mathbf{B}$ : Nuclear translocation of nuclear factor kappa-lightchain-enhancer of activated B cells; NO: Nitric oxide; PI3K: Phosphoinositide 3-kinases.

\section{REFERENCES}

1. DuPont $\mathrm{H}$. Acute infectious diarrhea in immunocompetent adults. New Engl J Med. 2014;370(16):1532-40.

2. Zimmermann M, Kotloff K, Nasrin D, Roose A, Levine MM, Rheingans R, et al. Household Costs of Diarrhea by Etiology in 7 Countries, The Global Enterics Mulitcenter Study (GEMS). Open Forum Infect Dis. 2019;6(4):ofz150.

3. Cavalcanti PMS, Martins MDCC, Nunes PHM, Alves FFC, Silva JDP, Cavalcanti SMG. Antidiarrheal effect of extract from the bark of Combretum leprosum in mice. An Acad Bras Cienc. 2019;91(1):e20170932.

4. Shah AJ, Bhulani NN, Khan SH, Rehman NU, Gilani AH. Calcium channel blocking activity of Mentha longifolia L. explains its medicinal use in diarrhea and gut spasm. Phytother Res. 2010;24(9):1392-7.

5. Nehlig A, Daval JL, Debry G. Caffeine and the central nervous system: mechanisms of action, biochemical, metabolic and psycho stimulant effects. Brain Research Brain Res Rev. 1992;17(2):139-70.

6. DeGonzalez ME, Ramirez-Mares MV. Impact of caffeine and coffee on our health. Trends Endocrinol Metab. 2014;25(10):489-92.

7. Nieber K. The Impact of Coffee on Health. Planta Med. 2017;83(16):1256-63.

8. Turnbull D, Rodricks JV, Mariano GF, Chowdhury F. Caffeine and cardiovascular health. Regul Toxicol Pharmacol. 2017;89:165-85.

9. Anonymous. Caffeine abuse may be missed in the ED. ED Manag. 2006;18(12):139-40.

10. DeOliveira EP. Runner's diarrhea: what is it, what causes it and how can it be prevented?. Curr Opin Gastroenterol. 2017;33(1):41-6. 
11. Mo L, Zeng Z, Li Y, Li D, Yan CY, Xiao S, et al. Animal study of the anti-diarrhea effect and microbial diversity of dark tea produced by the Yao population of Guangxi. Food Funct. 2019;10(4):1999-2009.

12. Awouters F, Niemegeers CJE, Lenaerts FM, Jannseen PAJ. Delay of castor oil-induced diarrhoea in rats: A new way to evaluate inhibitors of prostaglandins biosynthesis. J Pharm Pharmacol. 1978;30(1):41-5.

13. Kesherwani M, Gromiha M, Fukui K, Velmurugan D. Identification of novel natural inhibitor for NorM-A multidrug and toxic compound extrusion transporter: An in silico molecular modeling and simulation studies. J Biomol Str Dyn. 2017;35(1):58-77.

14. Sakkiah S, Thangapandian S, John S, Kwon YJ, Lee KW. 3D QSAR pharmacophore based virtual screening and molecular docking for identification of potential HSP90 inhibitors. Eur J Med Chem. 2010;45(6):213240.

15. Biaggioni ITALO, Paul SUBI, Puckett ANDR, Arzubiaga CARM. Caffeine and theophylline as adenosine receptor antagonists in humans. J Pharmacol Exp Ther. 1991;258(2):588-93.

16. Molecular Operating Environment (MOE), 2013.08. Chemical Computing Group ULC, 1010 Sherbooke St. West, Suite \#910, Montreal, QC, Canada, H3A 2R7, 2019. 2019.

17. Choubey SK, Prabhu D, Nachiappan M, Biswal J, Jeyakanthan J. Molecular modeling, dynamics studies and density functional theory approaches to identify potential inhibitors of SIRT4 protein from Homo sapiens: A novel target for the treatment of type 2 diabetes. J Biomol Str Dyn. 2017;35(15):3316-29.

18. Frisch MJ, Trucks GW, Schlegel HB, Scuseria GE, Robb MA, Cheeseman JR, et al. Gaussian, Inc., Wallingford CT. 2009.

19. Gleeson MP, Gleeson D. QM/MM calculations in drug discovery: A useful method for studying binding phenomena?. J Chem Inf Model. 2009;49(3):6707.

20. Wongchoosuk C, Udomvech A, Kerdcharoen T. The geometrical and electronic structures of open-end fully functionalized single-walled carbon nanotubes. J Curr Appl Phys. 2009;9(2):352-8.

21. Dennington R, Keith T, Millam J. GaussView, Version 4.1. Semichem Inc.; Shawnee Mission, KS, USA. 2007.

22. Calais J. Density-functional theory of atoms and molecules. RG Parr and W. Yang, Oxford University Press, New York, Oxford, 1989. IX+333 pp. Price£ 45.00. Int J Quantum Chem. 1993;47(1):101.

23. Pearson RG. Absolute electronegativity and hardness correlated with molecular orbital theory. Proc Natl Acad Sci. 1986;83(22):8440-1.

24. Pearson RG. The HSAB Principle - more quantitative aspects. Inorganica Chim Acta. 1995;240(1):93-8.

25. Mascolo N, Izzo AA, Barbato F, Capasso F. Inhibitors of nitric oxide synthetase prevent castor-oil-induced diarrhoea in the rat. $\mathrm{Br} \mathrm{J}$ Pharmacol. 1993;108(4):861-4.

26. Yoshio K. Relationship between antidiarrhoeal effects of Hange-Shashin-To and its active components. Phytother Res. 1999;13(6):468-73.

27. Bello FH, Maiha BB, Anuka JA. The effect of methanol rhizome extract of Nymphaea lotus Linn. (Nymphaeaceae) in animal models of diarrhoea. J Ethnopharmacol. 2016;190:13-21.

28. Uchida M, Kato Y, Matsueda K, Shoda R, Muraoka A, Yamato S. Involvement of nitric oxide from nerves on diarrhea induced by castor oil in rats. Jpn J Pharmacol. 2000;82(2):168-70.
29. Rawat P, Singh PK, Kumar V. Evidence based traditional anti-diarrheal medicinal plants and their phytocompounds. Biomed Pharmacother. 2017;96:1453-64.

30. Chang J, Fedinec AL, Kuntamallappanavar G, Leffler CW, Bukiya AN, Dopico AM. Endothelial Nitric Oxide Mediates Caffeine Antagonism of Alcohol-Induced Cerebral Artery Constriction. J Pharmacol Exp Ther. 2016;356(1):106-15.

31. Hwang JH, Kim KJ, Ryu SJ, Lee BY. Caffeine prevents LPS-induced inflammatory responses in RAW264.7 cells and Zebrafish. Chem-Biol Interact. 2016;248:1-7.

32. Leite-Morris KA, Kaplan GB, Smith JG, Sears MT. Regulation of G proteins and adenylyl cyclase in brain regions of caffeine-tolerant and -dependent mice. Brain Res. 1998;804(1):52-62.

33. Tariqul IAFM, Scavello M, Lotfi P, Daniel D, Haldeman P, Charest PG. Caffeine inhibits PI3K and mTORC2 in Dictyostelium and differentially affects multiple other cAMP chemoattractant signaling effectors. Mol Cell Biochem. 2019;457(1-2):157-68.

34. Li YF, Ouyang SH, Tu LF, Wang X, Yuan WL, Wang GE, et al. Caffeine Protects Skin from Oxidative Stress-Induced Senescence through the Activation of Autophagy. Theranostics. 2018;8(20):5713-30.

35. Köroğlu ÖA, MacFarlane PM, Balan KV, Zenebe WJ, Jafri A, Martin RJ, et al. Anti-Inflammatory Effect of Caffeine is Associated with Improved Lung Function after LPS-induced Amnionitis. Neonatology. 2014;106(3):235-40.

36. Kabir MSH, Hossain MM, Kabir MI, Ahmad S, Chakrabarty N, Rahman MA, et al. Antioxidant, antidiarrheal, hypoglycemic and thrombolytic activities of organic and aqueous extracts of Hopea odorata leaves and in silico PASS prediction of its isolated compounds. BMC Complement Altern Med. 2016;16(1):474.

37. Gong XP, Sun YY, Chen W, Guo X, Guan JK, Li DY, et al. Anti-diarrheal and anti-inflammatory activities of aqueous extract of the aerial part of Rubia cordifolia. BMC Complement Altern Med. 2017;17(1):20.

38. Lee IA, Low D, Kamba A, Llado V, Mizoguchi E. Oral caffeine administration ameliorates acute colitis by suppressing chitinase 3-like 1 expression in intestinal epithelial cells. J Gastroenterol. 2014;49(8):1206-16.

39. Esposito G, Capoccia E, Gigli S, Pesce M, Bruzzese E, D'Alessandro A, et al. HIV-1 Tat-induced diarrhea evokes an enteric glia-dependent neuroinflammatory response in the central nervous system. Sci Rep. 2017;7(1):7735.

40. Soliman ML, Geiger JD, Chen X. Caffeine blocks HIV-1 Tat-induced amyloid beta production and tau phosphorylation. J Neuroimmune Pharmacol. 2017;12(1):163-70.

41. Browning KN, Travagli RA. Central Nervous System Control of Gastrointestinal Motility and Secretion and Modulation of Gastrointestinal Functions. Compr Physiol. 2014;4(4):1339-68.

42. Cohen N, Benson SW. Estimation of heats of formation of organic compounds by additivity methods. Chem Rev. 1993;93(7):2419-38.

43. Aihara J. Reduced HOMO-LUMO Gap as an Index of Kinetic Stability for Polycyclic Aromatic Hydrocarbons. J Phys Chem A. 1999;103(37):7487-95.

44. Patil R, Das S, Stanley A, Yadav L, Sudhakar A, Varma AK. Optimized Hydrophobic Interactions and Hydrogen Bonding at the Target-Ligand Interface Leads the Pathways of Drug-Designing. PLoS One. 2010;5(8):e12029. 
PICTORIAL ABSTRACT
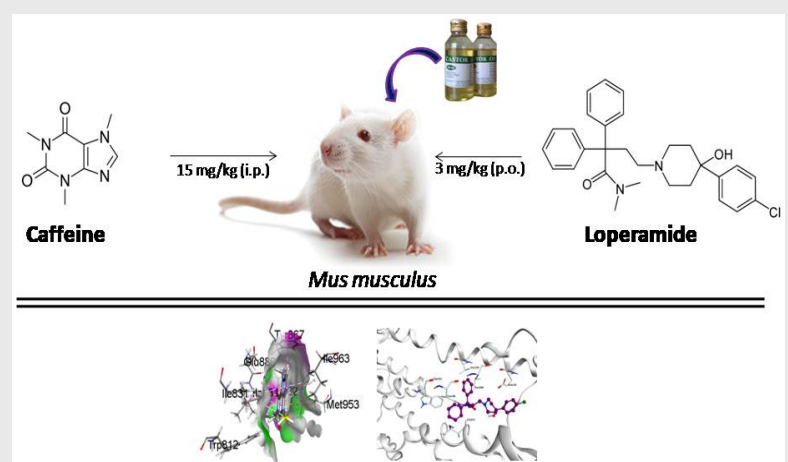

\section{$\Downarrow$}

Anti-diarrheal activity

\section{SUMMARY}

CAF at $15 \mathrm{mg} / \mathrm{kg}$ (i.p.) showed anti-diarrheal effect in castor oil-induced diarrheal mice. CAF co-treated with the standard drug, LOP exhibited better antidiarrheal effect in experimental animals. In in silico study, CAF showed strong binding affinity with the 6FH5 (PIK3CG) protein of the AR, while LOP with the $\mu$-OR which might be responsible for their synergistic anti-diarrheal effect in experimental animals. More investigations are highly appreciated to understand the exact molecular mechanism(s) behind the combined anti-diarrheal effect of CAF and LOP in animal model.
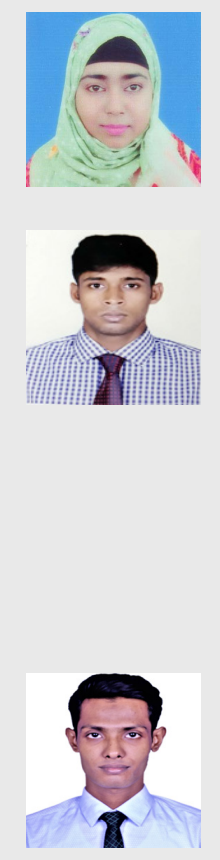

Farhana Faria, M.Pharm. student at the Department of Pharmacy at BSMRSTU, Gopalganj, Bangladesh. Her research lines are medicinal chemistry and drug discovery.

Shardar Mohammad Hafiz Hassan, student of Department of Clinical Pharmacy and Pharmacology at North South University, Dhaka, Bangladesh. His research area is drug discovery and development. $\mathrm{He}$ is expert in experimental studies, including in vitro, in silico and in vivo studies. Besides these, he has a keen interest in method development and pharmacology studies.

Rajib Hossain, M.Pharm. student at the Department of Pharmacy at BSMRSTU, Gopalganj, Bangladesh. His current research lines are cancer research, computational drug discovery and development, medicinal chemistry, pharmacology and phytochemistry.
Mahmuda Akter Mukta, M.Pharm. student at the Department of Pharmacy at BSMRSTU, Gopalganj, Bangladesh. Her research areas are drug discovery and development, infectious diseases, molecular biology, and medicinal chemistry.

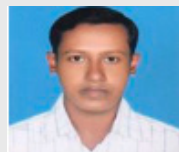

Md. Ashiqur Rahman Chowdhury, student of the Department of Chemistry at University of Chittagong. His research area is drug design and bioinformatics.

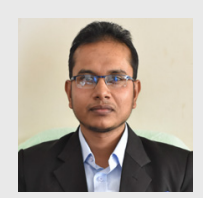

Dr. Muhammad Torequl Islam, working as an Assistant Professor at the Department of Pharmacy at BSMRSTU, Gopalganj, Bangladesh. His research lines are- drug discovery and development, method development, pharmacological and toxicological screenings. He is working collaboratively with more than 23 countries ( $>42$ institutions) in the world. RG Profile: https://www.researchgate.net/profile/ Muhammad_Islam108; ORCID: http:// orcid.org/0000-0003-0034-8202

Cite this article: Faria F, Hassan SMH, Hossain R, Mukta MA, Chowdhury MAR, Islam MT. Anti-diarrheal Activity of Caffeine: A Modulatory Effect with Loperamide and Through 6FH5 (PIK3CG) Protein Interaction Pathway. Indian $\mathrm{J}$ of Pharmaceutical Education and Research. 2020;54(3s):s601-s609. 